\title{
Severe hypoxemia during carinal resection in the lateral position under one-lung ventilation of a non-dependent lung -a case report-
}

\author{
Chang-Hoon Koo ${ }^{1}$, Yoo Sun Jung ${ }^{1}$, Yong-Hun Lee ${ }^{2}$, Hyun-Chang Kim³, \\ Jae-Hyon Bahk ${ }^{1}$, and Jeong-Hwa Seo ${ }^{1}$ \\ Department of Anesthesiology and Pain Medicine, ${ }^{1}$ Seoul National University Hospital, ${ }^{2}$ Asan Medical Center, \\ Seoul, ${ }^{3}$ Keimyung University Dongsan Medical Center, Daegu, Korea
}

\begin{abstract}
During one-lung ventilation (OLV) in the lateral position, the dependent, ventilated lung receives more blood flow than the non-dependent, non-ventilated lung owing to gravity, improving the match of ventilation and perfusion. Conversely, in the rare clinical situations when OLV is applied to the non-dependent lung, arterial oxygenation can get worse due to considerable shunt flow to the dependent non-ventilated lung. We report a case of severe hypoxemia during carinal resection under OLV of a non-dependent lung. In this case, OLV had to be applied to the non-dependent lung in the lateral position because the bronchus of the non-dependent lung was anastomosed with the trachea, whereas the bronchus of the dependent lung had already been resected for carinal resection. The subsequent hypoxemia resulting from the shunt flow to the dependent non-ventilated lung was treated successfully by ligating the pulmonary artery of the dependent lung.
\end{abstract}

Key Words: One lung ventilation, Perfusion, Thoracic surgery.

Thoracic surgery is generally performed in the lateral position with the non-dependent lung collapsed to improve surgical exposure, and one-lung ventilation (OLV) is applied to the dependent lung [1]. During OLV, more of the pulmonary blood flow is distributed to the dependent ventilated lung, improving

Corresponding author: Jeong-Hwa Seo, M.D., Ph.D.

Department of Anesthesiology and Pain Medicine, Seoul National University Hospital, 101, Daehak-ro, Jongno-gu, Seoul 03080, Korea

Tel: 82-2-2072-2467, Fax: 82-2-747-5639

E-mail: eongpa@empal.com

Received: March 19, 2015.

Revised: April 7, 2015.

Accepted: April 14, 2015.

Korean J Anesthesiol 2016 June 69(3): 279-282

http://dx.doi.org/10.4097/kjae.2016.69.3.279 the match of ventilation with perfusion and oxygenation [2]. Conversely, if OLV is applied to the non-dependent lung, even though it is clinically rare, the increased perfusion to the dependent non-ventilated lung might cause severe hypoxemia. Therefore, the strategy to reduce shunt flow is required for treatment of the hypoxemia. We report a case of severe hypoxemia during carinal resection in the lateral position under non-dependent OLV and its management by ligating the pulmonary artery of the dependent lung.

\section{Case Report}

A 39-year-old female (height $155 \mathrm{~cm}$, weight $44.5 \mathrm{~kg}$ ) with mild dyspnea was scheduled for carinal resection and reconstruction because of an adenoid cystic carcinoma in the carina. The chest computed tomography and bronchoscopy showed that

(c) This is an open-access article distributed under the terms of the Creative Commons Attribution Non-Commercial License (http://creativecommons.org/ licenses/by-nc/4.0/), which permits unrestricted non-commercial use, distribution, and reproduction in any medium, provided the original work is properly cited. 
the mass almost totally obstructed the left mainstem bronchus (LMB) and extended to the carina and right mainstem bronchus (RMB) (Fig. 1). Measuring on the chest computed tomography, the internal diameter (ID) and length of the RMB were 11 and $12 \mathrm{~mm}$, respectively; the length of the distal LMB not involved by the mass was about $20 \mathrm{~mm}$. She had no underlying diseases and her preoperative examinations were normal findings except moderate obstructive pattern of the pulmonary function test: A forced expiratory volume in one second of 1.88 liter (73\% of predicted value), forced vital capacity of 2.81 liter ( $86 \%$ of predicted value) and their ratio of $67 \%$.

General anesthesia was induced using target-controlled infusion of propofol $(4 \mu \mathrm{g} / \mathrm{ml})$ and remifentanil $(4 \mathrm{ng} / \mathrm{ml})$; rocuronium $40 \mathrm{mg}$ was administered for neuromuscular blockade.
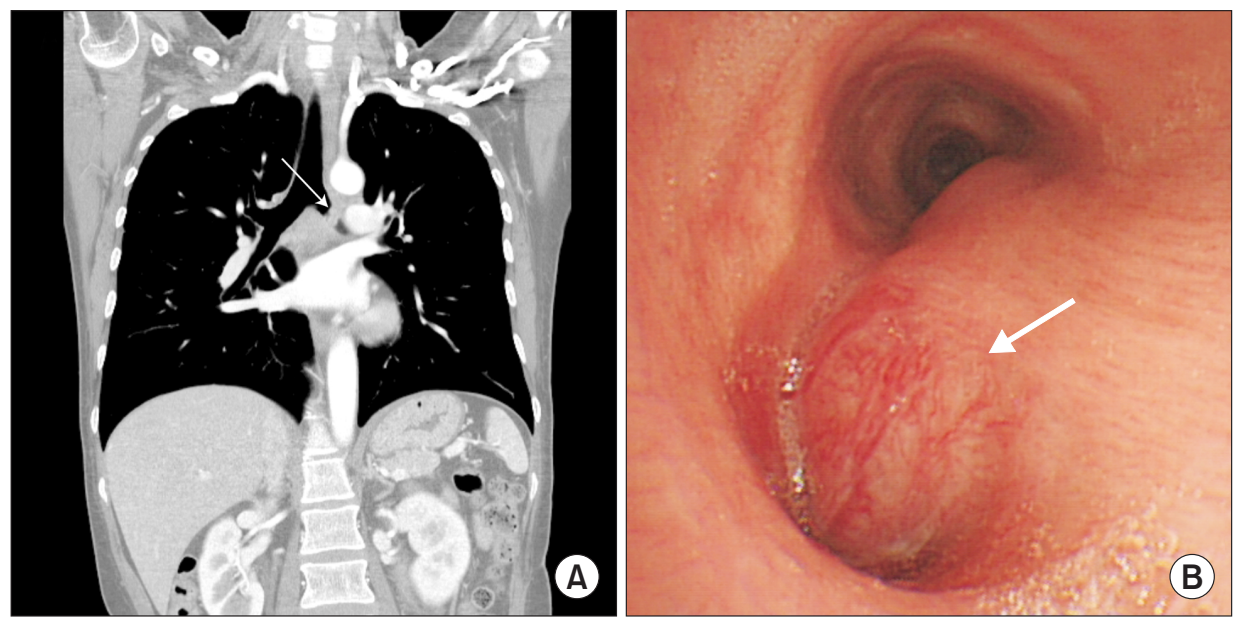

Fig. 1. Images of a chest computed tomography (A) and bronchoscopy (B) indicating the left endobronchial mass extending to the carina and right main stem bronchus (arrows).

A

$\mathrm{R}$

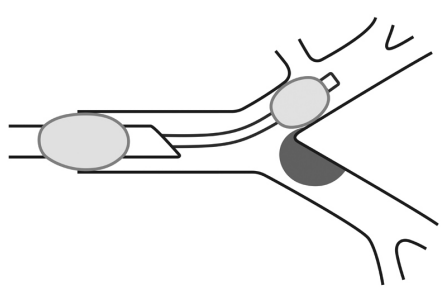

L

D

$\mathrm{R}$
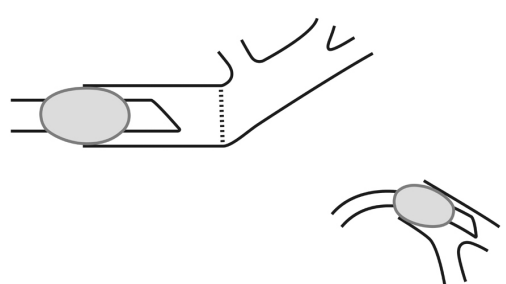

1
B

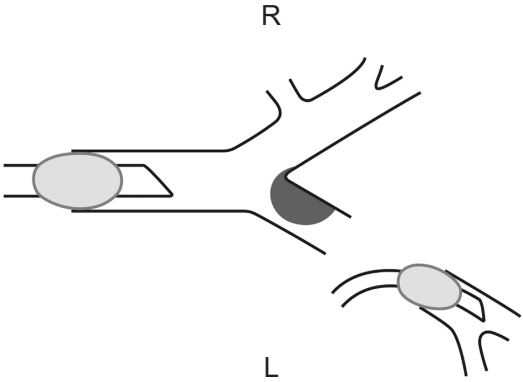

$E$

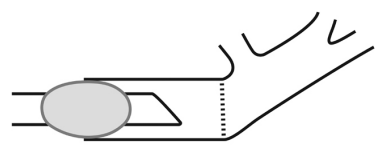

C

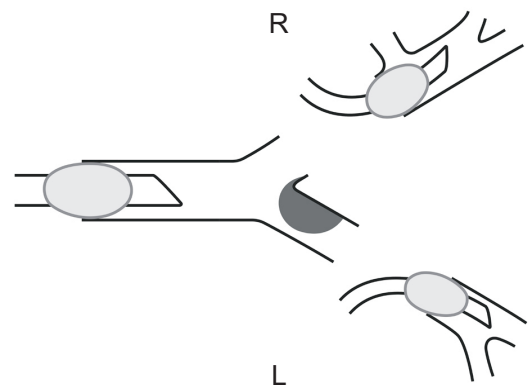

F

L

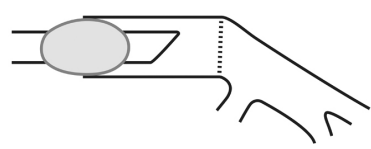

$\mathrm{R}$

Fig. 2. Schematic diagrams showing the surgical procedures for the carinal resection and left pneumonectomy. (A) Collapse of the right lung by a bronchial blocker inserted in the right main stem bronchus. (B) Resection of the left main stem bronchus, which was subsequently intubated with an aseptic endotracheal tube for left one-lung ventilation. (C) Insertion of an additional endotracheal tube into the resected right bronchus followed by differential bilateral lung ventilation. (D) Anastomosis between the trachea and right main stem bronchus, and subsequent bilateral lung ventilation. (E) Non-dependent right one-lung ventilation by the transoral tube. (F) Left pneumonectomy in the right lateral position. R: right hemithorax, L: left hemithorax. 
Tracheal intubation was performed using a 35-Fr right-sided double-lumen tube (Broncho-Cath ${ }^{\circledR}$, Covidien, Mansfield, MA, USA). The patient was moved to the right lateral position and left bronchi and vasculature were dissected by a thoracoscopic surgery under right OLV. Twenty minutes after OLV, the arterial oxygen tension $\left(\mathrm{PaO}_{2}\right)$ was $462 \mathrm{mmHg}$ on an inspired oxygen fraction $\left(\mathrm{FIO}_{2}\right)$ of 1.0.

After the left thoracoscopic surgery, the right-sided doublelumen tube was replaced with a single-lumen endotracheal tube of internal diameter $8.0 \mathrm{~mm}$, and a bronchial blocker (Coopdech, Daiken Medical, Osaka, Japan) was placed into the RMB under direct vision of a fiberoptic bronchoscope (LF-DP, olympus Optical, Tokyo, Japan) (Fig. 2A). After changing to the left lateral position, a right thoracotomy was done under left OLV, and the peak airway pressure was $28 \mathrm{cmH}_{2} \mathrm{O}$ at tidal volume $300 \mathrm{ml}$; the $\mathrm{PaO}_{2}$ was $110 \mathrm{mmHg}$ at an $\mathrm{FIO}_{2}$ of 1.0 after 20 min of left OLV. For the carinal resection, the LMB was resected and a sterile reinforced endotracheal tube of ID $6.5 \mathrm{~mm}$ was inserted into the separated LMB through the surgical field for ensuing left OLV (Fig. 2B). However, the airway pressure increased to $35 \mathrm{cmH}_{2} \mathrm{O}$ and the oxygen saturation by pulse oximetry $\left(\mathrm{SpO}_{2}\right)$ decreased to $70 \%$. To improve oxygenation by two-lung ventilation, the $\mathrm{RMB}$ was resected and an additional sterile endotracheal tube of ID $6.5 \mathrm{~mm}$ was also inserted into the separated right bronchus (Fig. 2C). Subsequently, the left and right lungs were ventilated using an anesthetic machine (Primus anesthetic workstation, Dräger, Lübeck, Germany) and a portable ventilator (Pneupac VR 1 Airmix, Smith Medical Ltd, UK), respectively; the $\mathrm{SpO}_{2}$ was restored to $100 \%$ after 2 min of the differential bilateral lung ventilation.

The carina was removed after resection of the lower trachea, and the separated RMB was anastomosed with the resected trachea (Fig. 2D). There was no air leak in the anastomotic site at $20 \mathrm{cmH}_{2} \mathrm{O}$ of airway pressure. However, the separated LMB was implanted to neither the trachea nor the right bronchus because it was too far away from the tracheobronchial tree, thus inevitably, the left lung was to be removed.

To close the opened right hemithorax, the left endobronchial tube was removed from the surgical field, and the non-dependent right lung was only ventilated by the transoral endotracheal tube (Fig. 2E). To reduce tension on the anastomotic site, the right lung was carefully ventilated with a low tidal volume of 200-250 $\mathrm{ml}$ to maintain an airway pressure lower than 20 $\mathrm{cmH}_{2} \mathrm{O}$. However, the $\mathrm{SpO}_{2}$ decreased below $80 \%$ under nondependent right OLV, thus the tube was immediately reinserted into the LMB and both lungs were ventilated. After sufficient two-lung ventilation at a $\mathrm{FIO}_{2}$ of 1.0 for $5 \mathrm{~min}$, right OLV was reattempted, but the $\mathrm{SpO}_{2}$ was gradually decreased below $90 \%$ after $3 \mathrm{~min}$ of OLV. To reduce a right-to-left shunt flow to the dependent left lung, we requested the surgeon to clamp the left pulmonary artery. Although an approach to the left pulmonary artery through the right hemithorax was difficult, the surgeon could compress the left main pulmonary artery with his fingers. In this situation, right OLV was attempted once again and we confirmed that $\mathrm{SpO}_{2}$ was maintained $100 \%$ more than 5 min under right OLV. The left main pulmonary artery was temporary ligated using a silicone vascular loop and a ligating clip and the left endobronchial tube was removed. Thereafter, the right thoracotomy was closed under right OLV without hypoxic events. One hour after ligating the pulmonary artery, the $\mathrm{PaO}_{2}$ was 360 $\mathrm{mmHg}$ at a $\mathrm{FIO}_{2}$ of 1.0.

After closing the right hemithorax, the patient was moved to the right lateral position, and a left thoracotomy was performed. The left pulmonary artery and veins were resected and the left pneumonectomy was completed (Fig. 2F). At the end of surgery, the patient was shifted to the supine position, and the chin was tightly sutured to the chest for preventing inadvertent hyperextension of the neck postoperatively. Tracheal extubation was gently performed when the patient breathed spontaneously and obeyed commands. The patient was transferred to the intensive care unit for close observation, and discharged on the 13th postoperative day without any complications.

\section{Discussion}

Carinal resection is a challenge for both thoracic surgeons and anesthesiologists because of complexity in surgical procedure and airway management $[3,4]$. A variety of airway devices and ventilator techniques are used for optimizing oxygenation and surgical exposure [5]. In our case, because any airway devices could not be placed in the LMB because of the left endobronchial mass, a right-sided double-lumen tube and a singlelumen tube with a bronchial blocker, which provide OLV with being placed into the RMB, were used for right and left OLV, respectively.

After cutting a bronchus for carinal resection, OLV is generally maintained by intubation of the resected bronchus using a sterile endotracheal tube in the surgical field [6]. For successful OLV, the length of the resected bronchus should be long enough to accommodate the distal part of the endotracheal tube. In our case, however, the resected LMB was shorter than $20 \mathrm{~mm}$, thus the distal part of the tube might be placed in a left lobar bronchus not in the main stem bronchus, resulting in one-lobe ventilation rather than OLV and impairing oxygenation. Moreover, the additional tube inserted into the resected RMB could not ventilate the right upper lobe because of short length of the RMB. Thereby, although bilateral lung ventilation might be incompletely achieved by three lobes, including right middle and lower lobes and left one lobe, oxygenation was adequately maintained. 
The obstructive endobronchial lesion chronically causes hypoventilation, which induces vasoconstriction of the ipsilateral lung and shifts more perfusion to the contralateral lung [7]. Therefore, in our case, although a preoperative lung perfusion scan had not been performed, the right lung might receive more blood flow than the left lung. Nevertheless, in contrast to the dependent right OLV which had provided adequate oxygenation during the left thoracoscopic surgery, the non-dependent right OLV induced severe hypoxemia after the tracheobronchial anastomosis. The primary reason for the hypoxemia would be the right-to-left shunt flow to the dependent non-ventilated left lung, because the hypoxemia was disappeared completely after eliminating the shunt flow by ligation of the left pulmonary artery. Although the role of gravity on the distribution of pulmonary blood flow is controversial in the supine or prone positions [8], in our case, the great difference in oxygenation during OLV according to the position of the ventilated lung shows that gravity is a major factor increasing the perfusion of the dependent lung in the lateral position.

As well as the effect of gravity, surgical compression and manipulation of the non-dependent lung can also impede its blood flow [9]. Moreover, the methods commonly used to re- duce atelectasis of the ventilated lung during OLV, such as the recruitment maneuver or high positive end-expiratory pressure [10], could not be applied in our case because we were afraid of increasing the tension in the tracheobronchial anastomosis. Consequently, potential atelectatic areas in the non-dependent ventilated lung might also increase the amount of shunt flow to the dependent non-ventilated lung.

Clamping the pulmonary artery of the non-ventilated lung eliminates the shunt flow completely, maximizing the match of ventilation and perfusion in the ventilated lung [11]. However, it might cause right ventricular overload or reperfusion lung injury, so it should be carefully applied for managing hypoxemia during OLV $[2,12]$.

In conclusion, during complicated airway surgeries, severe hypoxemia may occur by various clinical situations such as nondependent OLV, thus recognizing the pathophysiology of hypoxemia is essential. Non-dependent OLV in the lateral position can induce severe hypoxemia by considerable shunt flow to the dependent lung owing to the effect of gravity. The hypoxemia can be treated by reducing the shunt flow, such as by clamping the pulmonary artery of the dependent lung.

\section{References}

1. Benumof JL. One-lung ventilation and hypoxic pulmonary vasoconstriction: implications for anesthetic management. Anesth Analg 1985; 64: 821-33.

2. Brodsky JB. Approaches to hypoxemia during single-lung ventilation. Curr Opin Anaesthesiol 2001; 14: 71-6.

3. Regnard JF, Perrotin C, Giovannetti R, Schussler O, Petino A, Spaggiari L, et al. Resection for tumors with carinal involvement: technical aspects, results, and prognostic factors. Ann Thorac Surg 2005; 80: 1841-6.

4. Liu XY, Liu FY, Wang Z, Chen G. Management and surgical resection for tumors of the trachea and carina: experience with 32 patients. World J Surg 2009; 33: 2593-8.

5. Murthy T. Anaesthetic management of carinal resection and reconstruction-a case report. Indian J Anaesth 2009; 53: 340-3.

6. Weder W, Inci I. Carinal resection and sleeve pneumonectomy. Thorac Surg Clin 2014; 24: 77-83.

7. Bagan P, Le Pimpec-Barthes F, Badia A, Crockett F, Dujon A, Riquet M. Bronchial sleeve resections: lung function resurrecting procedure. Eur J Cardiothorac Surg 2008; 34: 484-7.

8. Glenny R, Robertson HT. Distribution of perfusion. Compr Physiol 2011; 1: 245-62.

9. Ishikawa S, Shirasawa M, Fujisawa M, Kawano T, Makita K. Compressing the non-dependent lung during one-lung ventilation improves arterial oxygenation, but impairs systemic oxygen delivery by decreasing cardiac output. J Anesth 2010; 24: 17-23.

10. Michelet P, Roch A, Brousse D, D'Journo XB, Bregeon F, Lambert D, et al. Effects of PEEP on oxygenation and respiratory mechanics during one-lung ventilation. Br J Anaesth 2005; 95: 267-73.

11. Watanabe T, Okada Y, Adachi O, Sado T, Toyama H, Noda M, et al. Contralateral pulmonary artery banding after single lobar lung transplantation. Ann Thorac Surg 2014; 97: 1429-31.

12. Gilbart E, Engelman E, Van der Linden P, Lerminiaux C, Vincent JL. Right ventricular function during pulmonary artery clamping: effects of enflurane. J Cardiothorac Anesth 1990; 4(Suppl 3): 118. 